\title{
CONSIDERAÇóES GERAIS SOBRE O SISTEMA DE "ROOMING-IN" (alojamento-conjunto)
}

* Wanda Escobar da Silva Freddi

** Maria Zofia B. Schubert

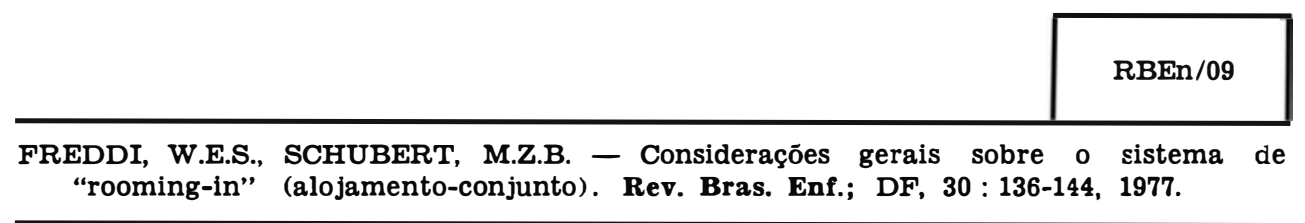

\section{A - INTRODUÇAOO}

A importância que o contato precoce do recém-nascido com a mãe, logo após o parto, apresenta no seu desenvolvimento emocional tem sido assunto para muitos estudos e pesquisas.

BUDIN (1970), famoso neonatologista, informa que as mães que eram separadas de seu bebê no período do pós-parto sentiam-se desinteressadas por ele. Além disso, mostravam-se incapazes de dispensar-lhe cuidados ou de criá-lo. O autor dá ênfase, principalmente, aos casos de mães de filho prematuro, comentando que muitas abandonaram o seu bebê. Para prevenir essa rejeição, BUDIN estimulava o aleitamento materno, pretendendo, com isso, um contato intimo entre mãe e filho.

Com o desenvolvimento das ciências que tratam do comportamento humano, os estudos sobre o significado do estímulo-resposta entre a mãe e o filho passaram a ter um interesse maior. Sem dúvida, o contato precoce entre ambos é muito valioso: se positivo, reflete-se beneficamente no desenvolvimento emocional da criança; se ineficiente, insuficiente ou negativo, pode ocasionar problemas futuros no relacionamento do novo ser com outros indivíduos do seu meio social.

DEUTCH (1952). concluiu, em suas pesquisas, que as influências e respostas similares de várias culturas são baseadas nas reações iniciais e primitivas entre a mãe e o filho. Para a autora, o amor da mãe é como um alimento e deve ser dado regularmente, aos poucos e freqüentemente.

KlaUS et al. (1970) realizaram um trabalho, com a finalidade de observar o comportamento da mãe no primeiro

* Professor Assistente Doutjr do Departamento de Enfermagem Materno-Infantil e Psiquiátrica da Escola de Enfermagem da USP.

* Professor Assistente do Departamento de Enfermagem Materno-Infantil e Psiquiátrica da Escola de Enfermagem da USP. 
FREDDI, W.E.S., SCHUBERT, M.Z.B. - Consideraçōes gerais sobre o sistema de "rooming-in" (alojamento-conjunto). Rev. Bras. Ene.; DF, 30 : 136-144, 1977.

contato com seu filho e determinar, até que ponto, 0 relacionamento precoce entre eles determina mudanças na atitude materna com relaçāo ao bebê. Utillizaram fotografias tiradas cada segundo, durante os dez primeiros minutos de contato, e estudaram o comportamento em doze māes de recém-nascidos de termo que foram colocados ao seu lado, desde meia hora até treze horas após o parto. Notaram, nessas māes, um comportamento progressivo e ordenado: elas começaram, tocando, com os dedos, as extremidades de seus recém-nascidos; e, após quatro ou oito minutos, faziam massagens no tronco do bebê, com a palma da mão. No primeiro contato, interessaram-se em observar o recémnascido "face a face", isto é, em mirálo. Os autores acharam que tais māes, que tiveram relacionamento precoce $\mathrm{e}$ prolongado com seu bebê, demonstraram maior preocupaçāo com o seu filho. Após um mês, quando foram entrevistadas novamente, acariaciavam, fitavam muito a criança durante a amamentaçāo e nāo permitiram que o pesquisador ficasse só, com ela. Isso quer dizer que a simples modifícaçāo de cuidados após o parto pode alterar o comportamento materno.

A interação entre māe e filho tem início no momento da concepçāo. $\mathrm{O}$ aumento da secreçāo hormonal durante a gravidez, necessário para manter o feto vivo, proporciona à māe ajustada uma sensaçāo de bem-estar. $O$ fenômeno fisiológico do crescimento do feto deve, portanto, ser acompanhado do preparo psicológico, que pode ser enfatizado no preparo da mulher para a maternidade. No parto e no pós-parto, há uma interrupçāo no processo de aproximaçāo do binômio mãe-filho. Nascido o bebê, várias māes não sentem desejo de amamentá-lo ou carregá-lo; no entanto, tudo isso pode ser despertado, à medida que a māe começa a cuidar da criança.

E útil lembrarmos que, para poder amar o seu bebê, a mãe necessita, nesse período, de amparo emocional e de comprensão e amor, tanto na parte de seus familiares como da do pessoal que forma a equipe de enfermagem. Quando o recém-nascido começa a sugar, ocorre, novamente, uma estreita aproximação entre māe e filho. Esse processo de dar e receber é muito gratificante para ambos: o bebê começa a associar suas necessidades de alimento e afeição com o novo meio em que vive e, dessa maneira, adquire confiança no mundo que o cerca; por outro lado, a mãe passa a desenvolver satisfaçāo pelo fato de considerar-se indispensável, o que a leva a sentir-se confiante e segura. E um mecanismo de duas vias.

Não podemos deixar de incluir, no binômio mãe-filho, os demais membros da família. $O$ preparo desses familiares para a nova situaçāo tem particular importância no ajustamento (especialmente no do pai, que precisa desenvolver o seu instinto paternal), ajustamento esse que influirá na aceitação do novo membro e no desenvolvimento do equilíbrio emocional do recém-nato.

YOUNGBLUT (1971) ressalta o valor de a mãe e o pai terem permissão e de receberem orientação para entrar nos berçários de terapia intensiva (observados todos os princípios de assepsia) e de poderem dar atendimento ao seu bebê, que lá se encontra. Essa autora sugere que haja, junto à unidade de berçário de cuidados intensivos, uma sala para os pais, para que eles possam conversar com o neonatologista ou com a enfermeira, bem como pegar seu filho ao colo e alimentá-lo.

IORIO (1975), comentando a assistência de enfermagem a puérperas, enfatiza o significado da orientaçāo dos pais para a alta hospitalar. De acordo com ela, tal orientação deve ser um processo contínuo, que principia no pré-natal e continua através de todo o ciclo da maternidade, tendo como principal objetivo descobrir as necessidades físicas e emo- 
FREDDI, W.E.S., SCHUBERT, M.Z.B. - Consideraçōes gerais sobre o sistema de "rooming-in" (alojamento-conjunto). Rev. Bras. Enf.; DF, 30 : 136-144, 1977.

cionais dos familiares. Recomenda, para o período de pós-parto, grupos de discussão sobre as precauçōes que a puérpera deve ter consigo mesma e com seu recém-nascido, partindo sempre do que ela sabe a respeito de suas novas atribuiçōes no regresso ao lar.

Outros autores, como LERCH (1970), FITZPATRICK et al. (1971), CLAUSEN et al. (1973) e outras, têm o mesmo conceito de IORIO (1975): consideram que a participação ativa da mãe no tratamento do bebê proporciona oportunidade de que suas deficiências sejam percebidas e ela receba orientação sobre como resolvê-las. Isso não só propicia satisfação para o filho como contribui para o amadurecimento materno. Nesse cuidado integrado, deve incluir-se a orientação do paí.

Considerando a importância do relacionamento precoce entre mãe e filho, como também do preparo do pai para receber o novo membro, KLAUS et al. (1970), LERCH (1970), FITZPATRICK et al. 1971), CLAUSEN et al. (1973), IORIO (1975) e outros apresentam o sistema de "Rooming-in" como o mais vantajoso em relação ao de berçário centralizado, para atingir aquele objetivo, KRINSKI et al. (1973) acrescentam um outro aspecto desse método: propōem dois tipos de isolamento nas maternidades: berçário de isolamento e "roomingin". Por razōes econômicas e epidemiológicas, preferiram o "rooming-in", em que os berços ficam junto ao leito materno: o bebê tinha alta junto com a mãe, fazendo-se a desinfecção do quarto.

Nesse processo, os recém-nascidos e as mães não entravam em contato com outras puérperas e bebês, os quais poderiam ter sido infectados com flora bacteriana do hospital. Segundo os autores, o risco de infecção proveniente da equipe hospitalar diminui; além disso, o isolamento dos quartos privativos e a permanente rotação da corrente de ar permitem que o desenvolvimento de focos endêmicos e o aparecimento de epidemias sejam eliminados.

Parece-nos, portanto, que as vantagens do sistema "rooming-in" (para a mãe, para o bebê e para a equipe profissional da unidade) merecem sérias consideraçōes.

\section{B - SISTEMA DE "ROOMING-IN"}

"Rooming-in", alojamento-conjunto ou bercário descentralizado é um sistema, no qual a assistência de enfermagem é dispensada tanto para a mãe quanto para o filho. Conforme já vimos, o berço do recém-nascido é colocado junto ao leito da puérpera, procurando proporcionar, o mais cedo possível, um relacionamento precoce - conduta utilizada, aliás, desde os tempos imemoráveis.

MEBRYDE (1951), revendo a história da assistência ao recém-nato, informa que, durante os noventa anos anteriores ao seu trabalho houve grandes mudanças quanto à responsabilidade da mãe nos bercários. Em 1880, nos hospitais da América e da Europa, "rooming-in" era o que prevalecia. No "Johns Hopkins Hospital", adotaram o berçário separado, mas ficaram usando "rooming-in" até 1890; o "Nursery and Children's Hospital" continuou a empregá-lo além de 1896 e o "New York Hospital", até depois de 1898.

Com a finalidade de diminuir a morbilidade e a mortalidade dos recémnascidos (geralmente resultantes de diarréias epidêmicas, infecçōes respiratórias e equipamentos inadequados), passou-se para o berçário centralizado. DUNHAM \& CRANE (1943) recomendaram, para os cuidados hospitalares do recém-nascido de termo e dos prematuros, no "Children's Bureau", medidas de proteção contra infecção e especificaram que as visitas nos berçários deveriam ser, exclusivamente, para as mães dos prematuros e através de visores. Também no manual da Academia Ame- 
FREDDI, W.E.S., SCHUBERT, M.Z.B. - Consideraçōes gerais sobre o sistema de "rooming-in" (alojamento-conjunto). Rev. Bras. Enf.; DF, 30 : 136-144. 1977.

ricana de Pediatria (1957), há a recomendação de isolamento rigoroso e a de visitas feitas unicamente através dos visores do berçário. Porém, segundo comentários do "Citizen's Committees on Children of New York City" (1955), em 1954, nesses hospitais, $50 \%$ dos bebês eram visitados apenas uma ou duas horas por semana. Após essa época, o trabalho apresentado por JACKSON et al. (1948) voltou a despertar o interesse dos neonatologistas e da enfermagem pela instalação do "rooming-in", para mães de crianças de termo.

No entanto, o "rooming-in" continua a ser discutido, com freqüência, como inovação moderna. Isso nos incentivou a analisar alguns dos aspectos desse método, orientando-nos, principalmente, pelas normas ditadas pela Academia Americana de Pediatria (1957).

\section{Objetivos do sistema de "rooming-in"}

Entre os objetivos do sistema de "rooming-in" destacamos os seguintes:

- proporcionar à mãe e à criança a experiência de um relacionamento precoce natural, logo após o parto, quando a puérpera se encontrar em condições de cuidar do seu bebê;

- incentivar a alimentação natural flexível, de acordo com as necessidades do recém-nato;

- orientar, tanto a mãe como o pai, quanto ao atendimento do recémnascido, para que eles sejam capazes de cumprir melhor a sua função e possam sentir maior segurança no cuidado do filho, após a alta hospitalar;

- reduzir ao mínimo a incidência de infecção cruzada entre os recémnascidos.

2. Tipos do sistema de "rooming-in"

Essencialmente, podemos ter três tipos do sistema de "rooming-in":
-- de permanência contínua;

- de permanência intermitente;

- de permanência obrigatória.

A escolha deve ser livre: a mãe é consultada sobre se aceita ou não o sistema e sobre qual deles prefere.

No sistema de permanência contínua, a criança fica todo o tempo ao lado da mãe. E, geralmente, o preferido pelas primiparas, que querem o filho o mais tempo possivel junto de si, para observar-lhes as reações e para aprender a tratar dele sob a orientação da enfermeira.

RIBEIRO et al. (1966) alertam para a conveniência de se oferecer, aos jovens pais, uma orientação segura no cuidado do filho; isso evitará levarem para casa um desconhecido que terão dificuldade de entender.

No sistema de permanência intermitente, o recém-nascido fica durante o dia com a mãe e, no período noturno, é recolhido para a unidade de berçário centralizado. O contato mãe-filho é menos prolongado do que no tipo anterior, porém, mais do que no sistema de berçário centralizado. Muitas mulheres dão preferência a tal modalidade, pois, durante a noite, podem descansar melhor; mesmo durante o dia, se estiverem cansadas e o bebê, irrequieto, podem pedir que ele seja removido para o berçário, até a mamada seguinte.

O sistema de permanência obrigatória é aplicado, quando há uma epidemia na unidade de berçário centralizado e o hospital não dispõe de instalações materiais adequadas de isolamento; portanto, só é indicado para resolver situaçōes de emergência. Nesse caso, todos os recém-nascidos, ficam, obrigatoriamente, junto à mãe. Na introdução de nosso trabalho, quando apresentamos a pesquisa de KRINSKI et al. (1973), já comentamos a validade desse método.

Cabe aqui, uma ressalva quanto às multíparas e às mães que têm atividades intensas no lar ou fora dele. Estas, 
FREDDI, W.E.S., SCHUBERT, M.Z.B. - Consideraçōes gerais sobre o sistema de

"rooming-in" (alojamento-conjunto). Rev. Bras. Enf.; DF, $30: 136-144,1977$.

de modo geral, preferem o sistema de berçário centralizado, pois querem aproveitar o tempo de permanência no hospital para repousar. Durante esse periodo, sentem-se livres da responsabilidade de cuidar do bebê e não têm ansiedade quanto ao que ele vai precisar receber, após a alta.

BASTOS (1969) considera contra-indicado o sistema de "rooming-in", nos casos em que a puérpera é portadora de moléstia infecciosa ou quando seu parto foi cirúrgico.

No caso de moléstia infecciosa, podendo esta ser transmitida ao recémnascido, este sistema não é, realmente, aplicável. Porém, nos de mulheres com complicações puerperais, LEIFER (1967) acredita firmemente que o "rooming-in" possa ser empregado, embora em princípio, seja reservado para puérperas sem intercorrências. Vai mais longe: acha que isso não só é possível, mas desejável, visando a preservar certos aspectos de independência e a incentivar o relacionamento natural entre mãe e filho. Segundo a autora, esse é um desafio para a enfermagem: ela deve preservar a independência da puérpera, estimular o relacionamento mãe-filho e manter as condições normais do puerpério. Para tanto, torna-se necessária uma assistência contínua, quer para a mãe, quer para o filho. Cumpre, então, à enfermeira, ter compreensão das necessidades físicas e emocionais da puérpera além de desenvolver um conceito real desta, como indivíduo.

\section{Requisitos prévios para o sistema de "rooming-in"}

A adoção do sistema de "rooming-in", nas maternidades, implica o estudo de certos requisitos relacionados com o pessoal (médicos, enfermeiras, auxiliares, pacientes e seus familiares) e com as instalações materiais. Todos os serviços hospitalares (administrativos ou de pes- soal) devem estar de acordo com o método adotado, para que a assistência à mãe e ao recém-nascido seja dada, homogeneamente, por toda a equipe que os assiste no ciclo grávido-puerperal. Destaca-se, de modo particular, a coordenação dos serviços de obstetrícia, pediatria, enfermagem e dietética.

\subsection{PESSOAL}

O pessoal da equipe hospitalar, tanto médicos como enfermeiras e auxiliares, necessita conhecer muito bem o método de "rooming-in", seus objetivos e as técnicas que serão utilizadas na assistência à mãe e ao bebê. Somente após treinamento poderão exercer, conscientemente, as funçōes. Aos médicos e às enfermeiras cabe despertar, na mãe e no pai, o interesse pelo cuidado integral do filho, desde o início. Além disso, os demais membros da família, como os outros filhos (se houver) ou os avós, precisam ser preparados para receber 0 novo membro. Portanto, para que o procedimento tenha sucesso, também os pais devem receber uma explicação completa sobre os seus objetivos e técnicas; e, se possível, visitar o hospital, antes do parto.

Um aspecto que convém ficar bem claro, seja para o pessoal hospitalar, seja para os pais, é o da limitação de visitas.

Se o sistema de "rooming-in" adotado for o intermitente, o recém-nascido poderá ser retirado da enfermaria nas horas de visita; se contínuo, as visitas serāo limitadas, permitindo-se apenas a visita do pai do bebê, dos avós e dos parentes mais próximos. Deve-se consentir apenas em um visitante por vez, exigidas as medidas profiláticas de rotina - lavagem das mãos, avental privativo, máscara e gorro - antes de a criança ser pega ao colo.

O êxito desse processo depende, em grande parte, da enfermeira: durante 
FREDDI, W.E.S., SCHUBERT, M.Z.B. - Consideraçōes gerais sobre o sistema de "rooming-in" (alojamento-conjunto). Rev. Bras. Enf.; DF, $30: 136-144,1977$.

todo o tempo, ela ou uma auxiliar de enfermagem permanece no atendimento da mãe e do recém-nascido, bem como ro dos seus familiares; além disso, tem que possuir uma preparação prévia, não só técnica, como também para elaborar, executar e avaliar programas de ensino adequados para orientar os pais na compreensão e no cuidado do filho. Segundo normas ditadas pela Academia Americana de Pediatria, uma enfermeira consegue atuar eficazmente somente com quatro mães e quatro recém-nascidos. Por conseguinte, "não se justifica a instalação desse método, com a finalidade de economizar número e tempo do pessoal de enfermagem.

\subsection{INSTALAÇŌES NECESSÃRIAS}

\section{I - Planta física}

Segundo RIBEIRO et al. (1966), o sistema de "rooming-in" exige uma "pequena ampliação da área dos quartos e enfermarias". Na realidade, as enfermarias e os quartos devem obedecer a certo padrão, tendo tamanho adequado para acomodar a mãe e os equipamentos necessários ao seu cuidado e ao do bebê. Várias plantas foram idealizadas, tendo desde um, até quatro leitos; contudo, ao se projetarem construções novas, será aconselhável que se planejem unidades de duas salas (cada sala para duas māes), dispostas ao redor de um espaço destinado à sala de serviço e de uma sala comum para quatro recém-nascidos. Recomenda-se que, qualquer que seja a enfermaria, apresente ela um espaço minimo de $7,5 \mathrm{~m}^{2}$ para cada cama, cadeira, mesa de cabeceira da mãe e berço, e tenha o material necessário ao cuidado do bebê. Cada enfermaria deve apresentar seu posto de enfermagem e uma sala para treinamento das mães. Sempre que possivel, esses quartos serão alegres, confortáveis e tranqüilos; se a construção for nova, recomenda-se o uso de material próprio a isolar ruídos.

Para BASTOS (1969), a unidade de berçário descentralizado ou "rooming-in" é um "pequeno berçário individual, colocado ao lado do quarto onde se localiza a mãe, deste separado por placa de vidro ou outro material transparente". A Academia Americana de Pediatria aconselha que, nas enfermarias de várias camas, estas sejam separadas com cortinas, ou com paredes delgadas laterais e cortinas, para que as puérperas possam desfrutar de certo isolamento; e que o berço permaneça ao lado da cama da mãe.

No planejamento do "rooming-in", é importante que toda enfermaria com uma ou mais puérperas junto com os filhos tenha uma pia, para facilitar a lavagem das mãos.

\section{II - Instalações para o recém-nascido}

Cada e n f e rmaria, no sistema de "rooming-in", deve conter, no mínimo:

- arm;rio embutido, para acondicionar a roupa limpa a ser usada no bebê (fraldas, cueiros, camisos etc.) e lençóis, toalhas etc.;

- material completo para o cuidado diário do recém-nascido e da mãe (individual) ;

- recipiente com tampa para colocar fraldas usadas e um outro, para demais roupas de que já se fez uso. Os dois devem ser colocados em um lugar cômodo para a mãe. Nas enfermarias de vários leitos, tais roupeiros não precisam ser individuais para cada mãe;

- aventais de manga longa, máscaras e gorros, em número suficiente para as visitas diárias.

\section{III - Alimentação artificial}

Embora uma das finalidades do sistema de "rooming-in" seja estimular a alimentação materna, muitas mães não 
FKEUDI, W.E.S., SCHUBERT, M.Z.B. - Consideraçôes gerais sobre o sistema de "rooming-in" (alojamento-conjunto). Rev. Bras. Enf.; DF, 30 : 136-144, 1977.

têm leite suficiente para o bebê e ele necessita de cumplementação alimentar. Nesses casos, o serviço de dietética prepara as mamadeiras, que são devidamente rotuladas e guardadas em refrigerador de berçário mais próximo; no horário da mamada, o alimento artificial é aquecido e levado para a mãe; completa-se assim, a alimentação natural.

\section{RESPONSABILIDADE DA ENFERMEIRA}

4.1. Observação, nas primeiras vinte e quatro horas de vida, do recém-nascido selecionado para o sistema de "roomingin".

Após o obstetra e o neonatologista recomendarem o sistema de "rooming-in", cabe à enfermeira fazer a observação rigorosa, tanto da mãe como do recémnascido. $O$ primeiro dia de vida é considerado o mais perigoso de todo o período neonatal; além disso, é importantíssimo que a enfermeira atente de modo especial, nos sinais e sintomas de intercorrências que podem surgir nessa fase. Ela precisa observar:

- tipo e freqüência de choro: o recémnascido deve chorar vigorosamente, sobretudo quando manipulado. Choro gemente, em grito ou soluço e ausência total de choro são indícios habituais de anomalias graves;

- cor da pele: notar se o recém-nascido apresenta palidez persistente (pode sugerir hemorragia interna, ocasionada por traumatismo do parto), cianose generalizada ou localizada e icterícia;

- freqüência respiratória: no recémnascido normal, a freqüência respiratória pode oscilar, nas primeiras vinte e quatro horas, entre quarenta e cinqüenta movimentos por minuto. Taquipnéia, com cianose perioral ou generalizada, deve ser comunicada ao neonatologista. Com as dificuldades respiratórias, costumam estar associados: náusea, vômito, posição anormal da cabeça e tremores musculares - sintomas, que podem ser ocasionados por obstrução da naso-faringe devida a muco ou secreção. $O$ bebê deve ser aspirado e colocado em posição de drenagem postural (Trendelemburg);

- eliminações: as primeiras fezes precisam ser observadas quanto à cor, ao aspecto e ao cheiro, e o fato, anotado, rigorosamente, no prontuário do recémnascido. Isso indica o seu funcionamento intestinal. O mesmo procedimento, com relação à eliminação de urina. $O$ vômito hemoptóico ou com sangue coagulado e a malena notificam-se ao neonatologista, urgentemente;

- observação do coto umbilical, para controlar hemorragia; quando necessário, fazer nova laqueadura;

- tremores acentuados dos membros superiores e inferiores exigem especial atenção, pois podem significar hipoglicemia ou hipocalcemia; informar o neonatologista a respeito, pois, nesses casos, testes laboratoriais esclarecem o diagnóstico;

- transpiração: ocorre, às vezes, entre as duas e as seis primeiras horas de vida; freqüentemente, a transpiração está associada ao choro e à dificuldade do bebê em eliminar o mecônio.

Essas observaçōes são valiosas, porque os recém-nascidos que apresentam qualquer alteração, ou suspeita de alguma anomalia, devem permanecer no berçário central, não sendo conveniente que venham a colocar-se em sistema de "rooming-in".

\subsection{Orientação dos pais.}

Durante o tempo de permanência no hospital, é bastante vantajoso que a mãe seja ensinada a cuidar do bebê, sob a orientação direta da enfermeira. Assim, ela adquire confiança na sua habilidade de tratar do filho. Também o pai deve participar de algumas aulas e dispensar cuidaços à criança, para conhecê-la me- 
FREDDI, W.E.S., SCHUBERT, M.Z.B. - Consideraçōes gerais sobre o sistema de "rooming-in" (alojamento-conjunto). Rev. Bras. Enf.; DF, 30 : 136-144, 1977.

lhor e poder auxiliar a esposa, após a alta hospitalar. Isto aumenta a segurança dos pais e melhora o relacionamento familiar.

Como sugestāo para a orientaçāo dos pais, a enfermeira deverá fazer, junto com os outros profissionais que cuidam da māe e do bebê, um programa que tenha, no mínimo, os seguintes assuntos:

- principais características físicas do recém-nascido: peso, aparência física, postura, forma da cabeça, cabelo, laringe, olhos, coto umbilical, ellminações e pele;

- principais necessidades emocionais do bebê e como satisfazê-las: necessidade de afeto, amor e aconchego maternos; necessidade de sono; tipos e causas do choro do bebê;

- amamentação natural: vantagens; técnica correta para a amamentação natural;

- alimentaçāo artificial e complementar: cuidados com os utensílios usados no preparo da fórmula láctea; técnica do preparo da fórmula láctea;

- tratamento diário do recém-nascido: banho antes e após a queda do coto umbilical; limpeza, antes das mamadas;

- modificações dos primeiros dias de vida: icterícia fisiológica; fezes e suas características (mecônio, transiçāo e normais); pseudomenstruaçāo, tumefaçāo mamária e hidrocele;

- equipamento e enxoval do bebê;

- exame médico periódico;

- registro de nascimento;

- precauções que a puérpera deve ter consigo mesma, durante o puerpério.

\section{C - CONSIDERAÇÓES FINAIS}

O sistema de "rooming-in" não se limita a aprimorar a assistência à mãe e au recém-nascido; proporciona também um intercâmbio emocional harmonioso entre os familiares, o que vai influir na formaçāo da estrutura psicofísica da criança e no seu ajustamento ao mundo exterior.
Nestas considerações finais, apresentamos, resumidamente, suas vantagens e desvantagens.

Vantagens:

- facilita o relacionamento mãe-filho;

- diminui, ao mínimo, a possibilidade de infecçāo cruzada;

- permite melhor supervisāo do recém-nascido, pois a māe presta mais atençāo ao filho do que a enfermeira ou a obstetriz;

- diminui a possibilidade de troca de bebês (a maior fonte de problemas da administraçāo hospitalar);

- aumenta a possibilidade de orientaçāo da māe e dos seus familiares, quanto à asisstência ao recém-nascido.

COX (1974) acrescenta, ainda, as seguintes:

- nos casos de incêndio ou em qualquer outra emergência que exija rápida retirada dos bebês, as mães podem sair rapidamente, levando seus filhos;

- em instituições hospitalares, há o risco de indivíduos com distúrbios mentais lesarem pacientes que podem defender-se; no sistema de "rooming-in", pela constante vigilância materna, tal risco se reduz. Em berçários centralizados, o número de pessoal é, via de regra, insuficiente; por conseqüência, a vigilância dos recém-nascidos é menor.

Desvantagens:

- perda de sono da mãe. O choro do bebê ou um grito dele pode acordar todas as māes (geralmente as enfermarias sāo de quatro leitos e um bebê, chorando ou gritando, acorda as quatro mães). evidente que a enfermeira removerá depressa, para o berçário central, o bebê que estiver chorando;

- exige um contingente maior de pessoal, para dar assistência de enfermagem (incluindo a orientação da māe e a dos familiares) como ainda para controlar o suprimento e a limpeza das enfermarias; 
FREDDI, W.E.S., SCHUBERT, M.Z.B. - Consideraçōes gerais sobre o sistema de "rooming-in" (alojamento-conjunto). Rev. Bras. Enf.; DF, 30 : 136-144, 1977.

- a orientação e a supervisão do serviço do pessoal da equipe são mais difíceis;

- há maior consumo de material.

Considerando as vantagens e as desvantagens do sistema de "rooming-in", achamos que, na medida do possível, convém que ele seja implantado. Isso im- plica a mudança de atitude da equipe profisisonal, que, uma vez favorável à utilização do método, deve estudar o melhor caminho para alcançar plenamente os seus objetivos. Mesmo porque o comportamento do pessoal em relação ao sistema de "rooming-in" é muito mais importante do que as facilidades materiais que o hospital possa apresentar.

\section{REFERENCIAS BIBLIOGRAFICAS}

BUDIN, P. The nursing. London, Caxton, 1907. YOUNGBLUT, A. C. Specially for the newborn intensive care in the nursery. CanNurse, 67: 24-7, aug. 1971.

MCBRYDE, A. Compulsory rooming-in in the ward and private newborn service at Duke Hospital. J.A.M.A., 145: 625, 1951.

JACKSON, et al Hospital rooming-in unit for 4 newborn infants and their mother: descriptive account of background, development, and procedure with fero preliminary observations. Pediatrics, 1: 28, 1948.

DEUTCH, H. La psicologia de la mujer. 4." ed. Buenos Aires, Losada, 1960. v. 2.

KLAUS, M. $\mathrm{H}$ et al. Human maternal behavior at the first contact with her young. Pediatrics, 46 (2): 187-192, August, 1970.

IORIO, J. Childbirth-family-centered nursing. 3 rd. Saint Louis, Mosby, 1975.

CLAUSEN, J. P. et al. Maternity Nursing Todoy. New York. McGraw-Hill, 1973.

FITZPATRICK, E. et al. Maternity Nursing. 12nd ed. Philadelphia, lippincott, 1971.

LFRCH, C. Maternity nursing. Saint Louis. Mosby, 1970.

ERYNSRI, et al. Application of cohort isolation principles to the rooming-in of babies and their mothers in hospital staphilococcal cross-infections. J. Hig. Epidemiol. Microbiol. Immunol. 17: 323-8, mar. 1973.

DUNHAM, E. \& CRENE, M. Standards and Recomendations for Hospital Care of Newborn Infanta, Full - Term and Premature. U. S. Children's Bureau, Washington, Bureau of Publications, 1943. (Publication número 242).

ACADEMIA AMERICANA DE PEDIATRIA Normas y recomendaciones para la atención del recién nacido en hospitales a término y prematuro. Evanston, Academia Americana de Pediatria, 1957.

CITIZENS' COMMTTTEE ON CHILDREN OF NEW YORK CITY. J. Pediat., 46: $710,1955$.

RIBEIRO, C. $M$. et \& AUGUSTO, E. P. Unidade de enfermagem obstétrica. Revista Paulista de Hospitais. 14 (9): 8-20. Set. 1966.

BASTOS, N. M. Berçário centralizado ou descentralizado? Revista Paulista de Hospitais, 17 (7): 11-18, jul. 1969.

LEIFER, G. Rooming-in despite postpartal complications. American Journal of Nursing, 67 (10): 2.114-2.119, oct., 1967.

COX, B. S. Rooming-in. Nursing Times: 1.246-1.247, Aug. 8, 1974. 